\title{
A Conducting Composite of Polythiophene: Synthesis and Characterization
}

\author{
Fatma Vatansever, Jale Hacaloglu, Ural Akbulut \& Levent Toppare* \\ Department of Chemistry, Middle East Technical University, 06531 Ankara, Turkey
}

(Received 12 March 1996, accepted 16 April 1996)

\begin{abstract}
Conducting polymer composites of polythiophene, using a polyamide as the insulating matrix, were prepared via electrochemical methods. The characterization of the composite was done by scanning electron microscopy, differential scanning calorimetry, thermogravimetric analysis, Fourier transform infrared and pyrolysis studies. The conductivities were measured by a four-probe technique. The cited methods revealed that the composites have properties different from those of simple mechanical mixtures of the two polymers.
\end{abstract}

Key words: conducting polymer composite, polythiophene, pyrolysis, mass spectrometry.

\section{INTRODUCTION}

Conjugated polymers are of special interest because of the potential for a unique combination of electrical and mechanical properties. The high electrical conductivity of heteroatomic polymers, such as polythiophene (PTh), polyaniline, polypyrrole and polyfuran, have spurred interest in the use of these materials for electronic and chemical applications. ${ }^{1-5}$ There have been various studies on the synthesis of such polymers and their derivatives. ${ }^{6-12}$ Several groups have reported that their electrochemical polymerization can be carried out on an electrode coated with an insulating polymer. ${ }^{13,14}$ The main aim is to obtain homogeneous composites having the properties of both polymers, at least to a certain extent. It is known that these heterocyclic polymers possess poor mechanical properties and processability. In recent years, several attempts have been made to overcome these problems, ${ }^{15-18}$ in particular by blending with conventional polymers. However, mechanical blending is undesirable, because the conductivity

* To whom all correspondence should be addressed. Present address: Department of Chemistry, Bilkent University, 06533 Ankara, Turkey. of the polymer decreases, whereas during electrochemical synthesis of the conducting polymer on an electrode coated with an insulating polymer, the conductivity of the resultant electrolytic film is maintained and the mechanical properties are improved. This paper concentrates on the synthesis and characterization of homogeneous composites of polythiophene on a polyamide (PA) coated electrode. The characterization of the freestanding films was done by means of scanning electron microscopy (SEM), differential scanning calorimetry (DSC), thermogravimetric analysis (TGA), Fourier transform infrared (FTIR) and direct and indirect pyrolysis mass spectrometry (MS) analyses.

\section{EXPERIMENTAL}

PTh/PA composites were prepared by electrochemical polymerization of thiophene onto a PA-coated electrode at a constant potential of $+1.8 \mathrm{~V}$ versus a $\mathrm{Ag}^{0} / \mathrm{Ag}^{+}\left(10^{-2}\right)$ reference electrode. The electropolymerizations were carried out with a potentioscan Wenking POS 73. 
The PA films were dip-coated from chloroform solution $\left(10 \mathrm{mgl}^{-1}\right)$ of a commercial polyamide resin (Aldrich Co. 19, 101-9; a 20-carbon aliphatic amide with $T_{\mathrm{m}}=95^{\circ} \mathrm{C}$ ). The amounts of insulating and conducting polymer were gravimetrically determined.

The polymerizations were carried out in a threecompartment cell equipped with Pt foils $\left(1.5 \mathrm{~cm}^{2}\right)$, as the working and the counter electrodes, and a capillary $\mathrm{Ag}^{0} / \mathrm{Ag}^{+}$as the reference electrode. The solvent was acetonitrile (Aldrich Co. 27, 071-7), and the electrolyte was tetrabutylammonium tertrafluoroborate (Aldrich Co. 21, 7966-4). To be sure that there were no changes in the structure or in the weight of the insulating polymer, blank runs with PA-coated electrodes were carried out in the same medium containing no thiophene. ${ }^{19}$

Conductivities of the samples were measured via a four-probe technique. The composites were characterized by FTIR (Nicolet 510 FT-Spectrometer), DSC (TA Instruments Thermal Analyst 2000 System), TGA (Du Pont Instruments 951 Thermogravimetric Analyzer) and SEM (JEOL JSM-6400 Scanning Microscope). The experimental set-up used in direct and indirect pyrolysis analyses by MS has been explained in detail in our previous publications. ${ }^{20,21}$ Direct pyrolysis MS equipment basically consists of a direct insertion pyrolysis probe designed in our laboratories, a Balzers QMG 311 quadruple mass spectrometer and a personal computer for the control of the instrument and data acquisition and processing. In the case of indirect pyrolysis MS studies for the analysis of evolved gases, a pyrolysis chamber was used instead of the probe.

\section{RESULTS AND DISCUSSION}

The electro-oxidation of thiophene on a PA-coated anode gives rise to a film whose colour changes from green to black as the doping state increases.

Free-standing films were obtained by peeling them off the electrode surface. Since the films are highly affected by moisture in the air, they were dried under vacuum and kept in dry $\mathrm{N}_{2}$ atmosphere before conductivities were measured. The relation between the conductivity and the composition of the free-standing films is given in Fig. 1. A threshold conductivity of about $0 \cdot 1 \mathrm{~S} \mathrm{~cm}^{-1}$ is reached at c. 30\% PTh content in the composite films.

When the films were washed with chloroform (the solvent for PA) for several weeks, no changes were found in the weight; the films did not dissolve even when they were refluxed in chloroform for several days. The surface appearance of the washed and unwashed films remained the same, as did the conductivity. SEM micrographs of the composites show that PTh grows uniformly in the host polymer (PA). Polythiophene crests grow out of the surface of the coated electrode toward the solution, producing the so-called cauliffower picture (Fig. 2). These observations indicate that there is a certain chemical interaction other than a simple physical adhesion in between the two polymers.

The DSC studies (Fig. 3) show different thermal behaviours for PA, PTh, PA-PTh simple mechanical mixture and the electrolytic film. The glass transition temperature $\left(T_{\mathrm{g}}\right)$ of $\mathrm{PA}$ is around $88^{\circ} \mathrm{C}$ and in the mechanical mixture the same can clearly be seen, whereas in the electrolytic film no $T_{\mathrm{g}}$ due to PA was

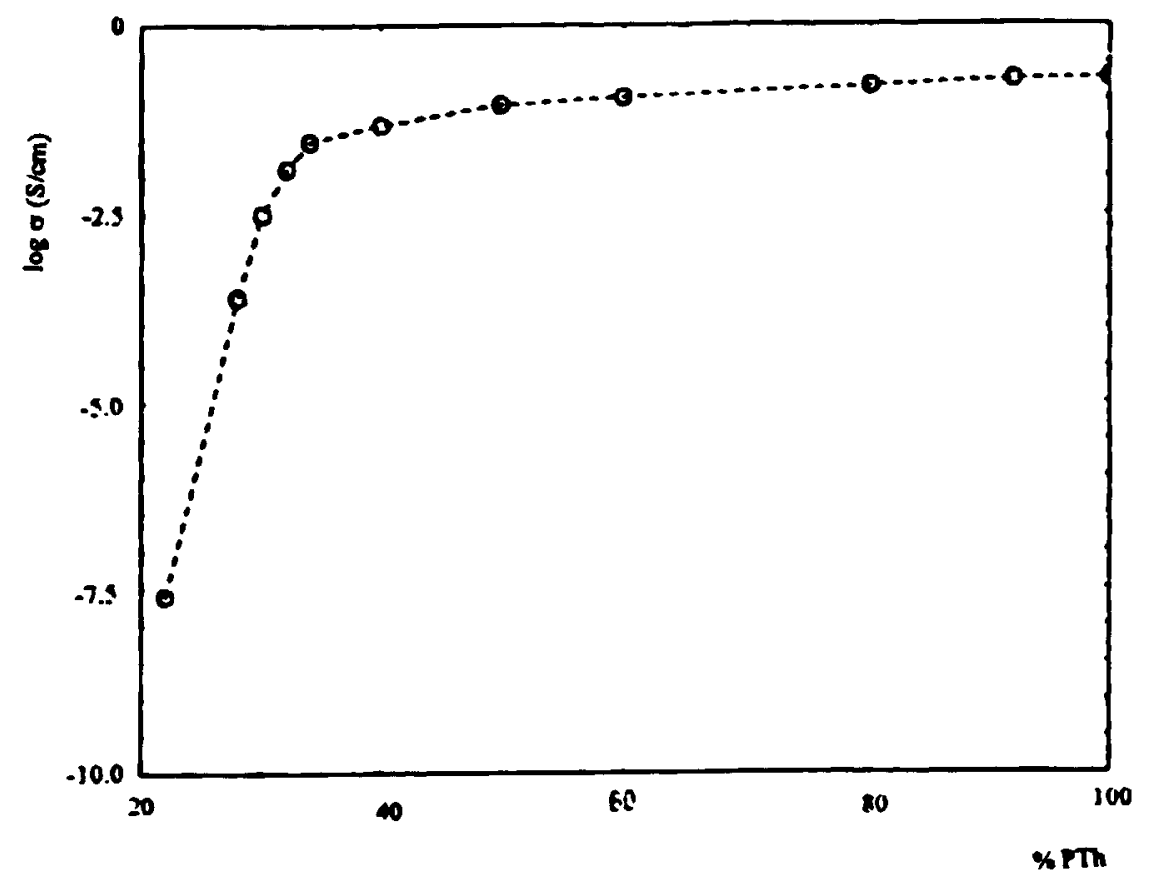

Fig. 1. Conductivities of PA/PTh films. 

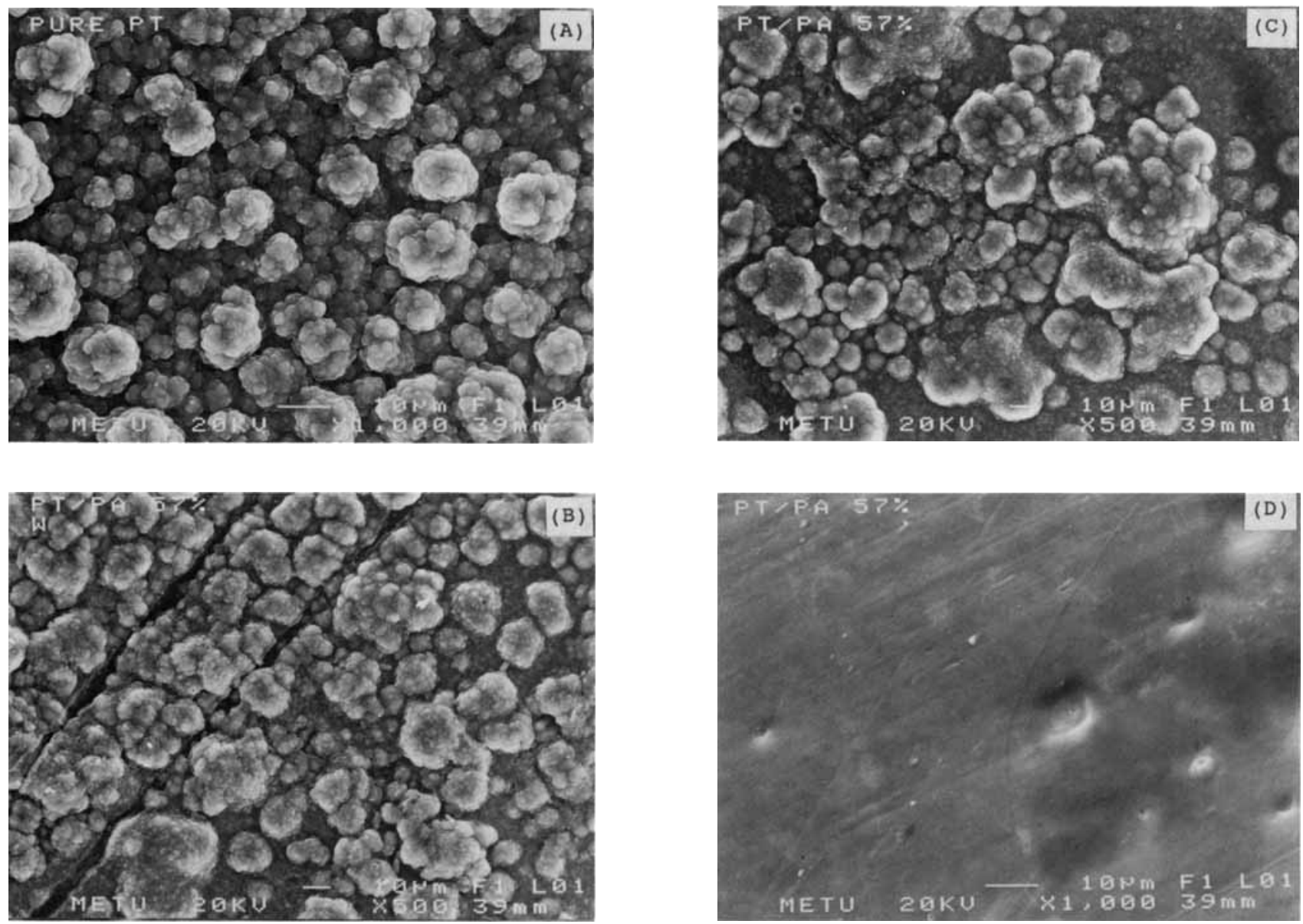

Fig. 2. SEM micrographs: (A) pure PTh, solution side; (B) PTh/PA electrolytic film, solution side; (C) washed PTh/PA electrolytic film; (D) PTh/PA electrolytic film, electrode side.

observed. The mechanical mixture shows the thermal behaviour of the PA $\left(c .80^{\circ} \mathrm{C}\right)$ and that of PTh $(c .205$ and $300^{\circ} \mathrm{C}$ ), whereas the electrolytic film reveals a different endotherm at around $107^{\circ} \mathrm{C}$.

Thermogravimetric analysis of the electrolytic films shows different patterns to that of the mechanical mixture of the two polymers (Fig. 4). There is no loss peak for PA in the case of the electrolytic film, while for the mechanical mixture the loss peak due to PA is clearly evident. This weight loss pattern for the composite film can be considered as evidence of higher heat resistance, with no indication of the presence of free polyamide. This conclusion is based on the absence of a $445^{\circ} \mathrm{C}$ peak, which is only due to the insulating polymer.

FTIR spectra of the pure polymers and their mechanical mixture are studied in comparison with that of the composite films (Fig. 5). The electrolytic free-standing film [Fig. (5(D)] has a somewhat different pattern compare to the mechanical mixture [Fig. 5(C)], especially in the low wavenumber region.

In order to be more specific as to the differences in the spectra, pyrolysis studies were carried out. Studies on thermal stabilities and degradation products of the
PA, PTh, the mechanical mixture and the electrolytic film (PA/PTh) by direct and indirect pyrolysis MS techniques offer another means of assessing the nature of the product. Direct pyrolysis mass spectra of PA and PTh samples were quite typical.

Characteristic peaks of both long hydrocarbon chains and amide groups were present in the direct pyrolysis mass spectra of PA. The main decomposition occurred in a narrow temperature range of 215 to $235^{\circ} \mathrm{C}$. Maximum product yield was observed at $226^{\circ} \mathrm{C}$. In the case of PTh, the decomposition started at very low temperatures, just above $50^{\circ} \mathrm{C}$, mainly yielding small molecular weight fragments.

Diagnostic peaks for both PA and PTh were present in the direct pyrolysis mass spectra of the mechanical mixture. The thermal behaviour of each component resembled that of the corresponding homopolymer. On the other hand, direct pyrolysis of the electrolytic film produced notably different spectra. Disappearance of the diagnostic peaks for PA was particularly significant. Figure 6 shows the variation of the relative intensity (intensities are given relative to the normalized base peak in the pyrolysis mass spectra of each sample) of the peak at $140 \mathrm{amu}$, due to characteristic cleavage of 

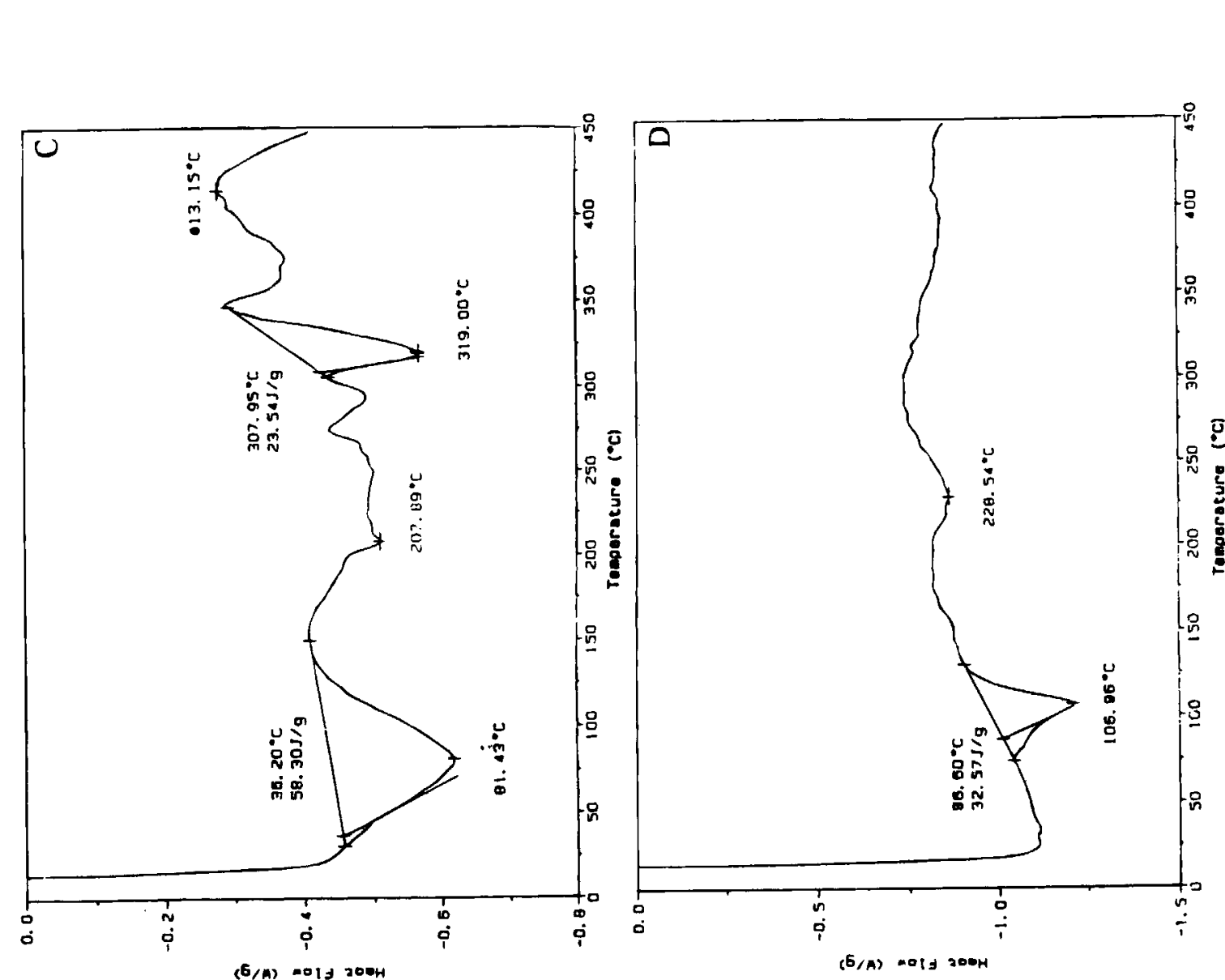

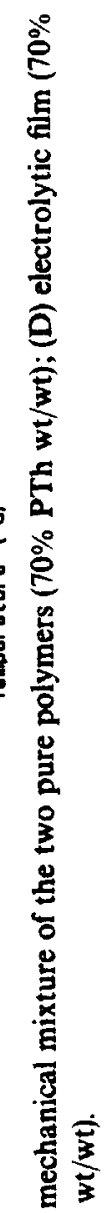
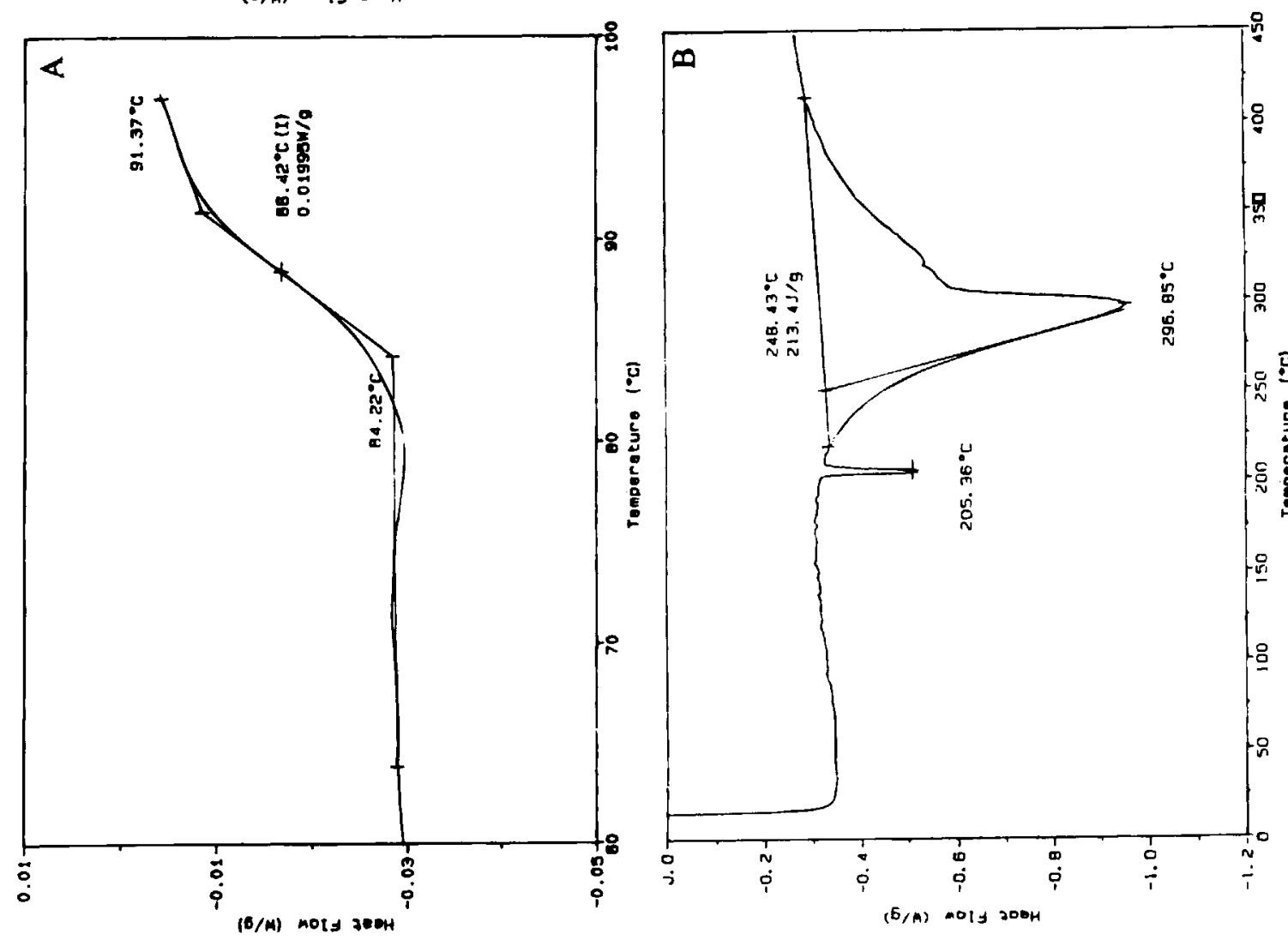

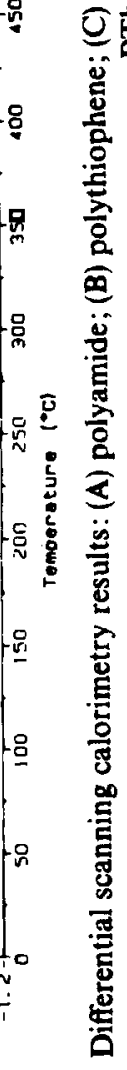

实 

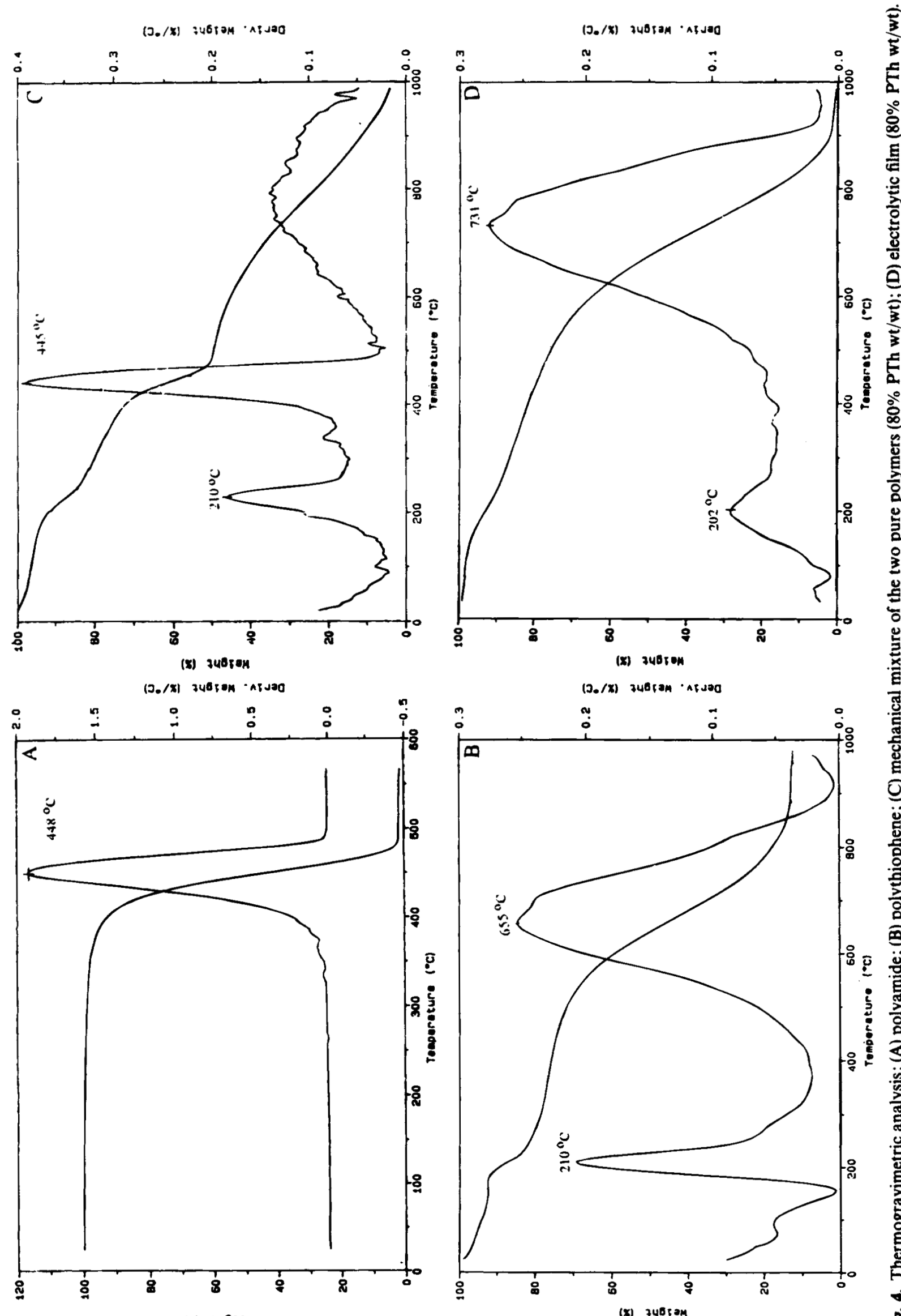

(3./x) zugran insugo

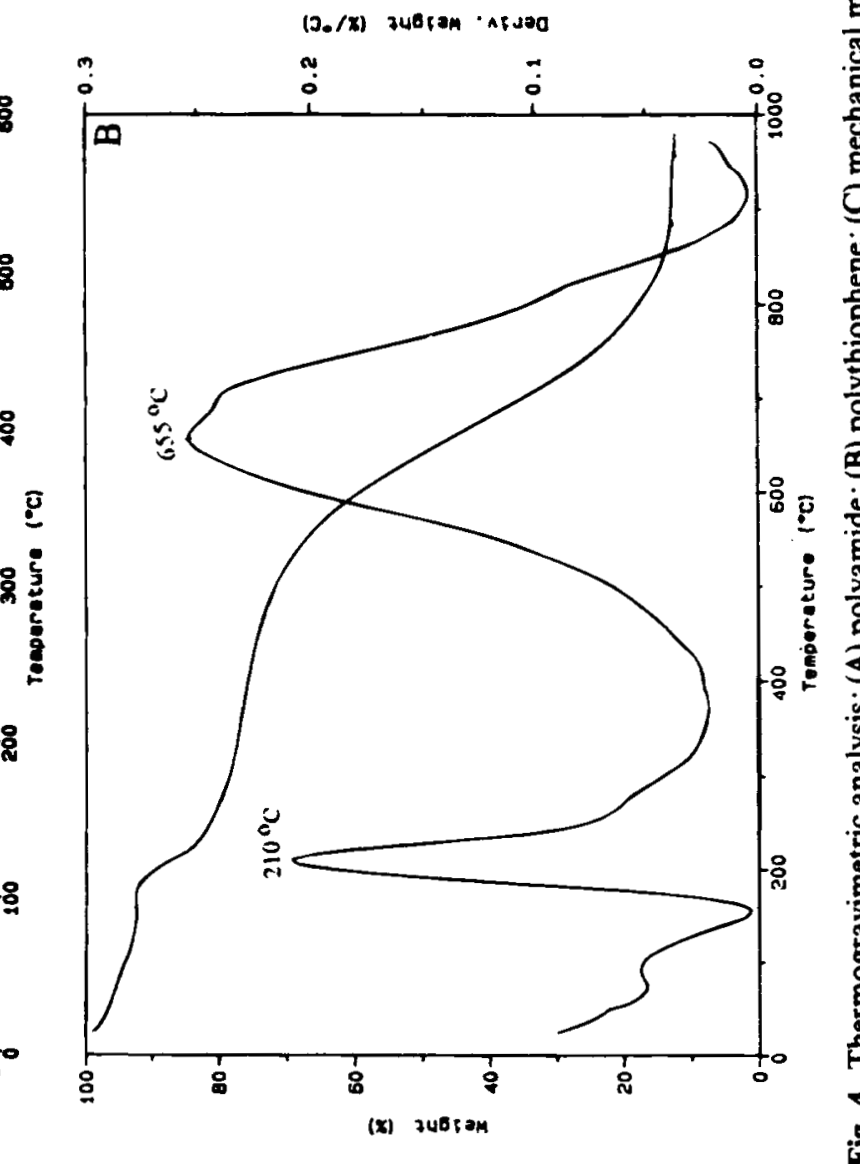

(s) 340tox 

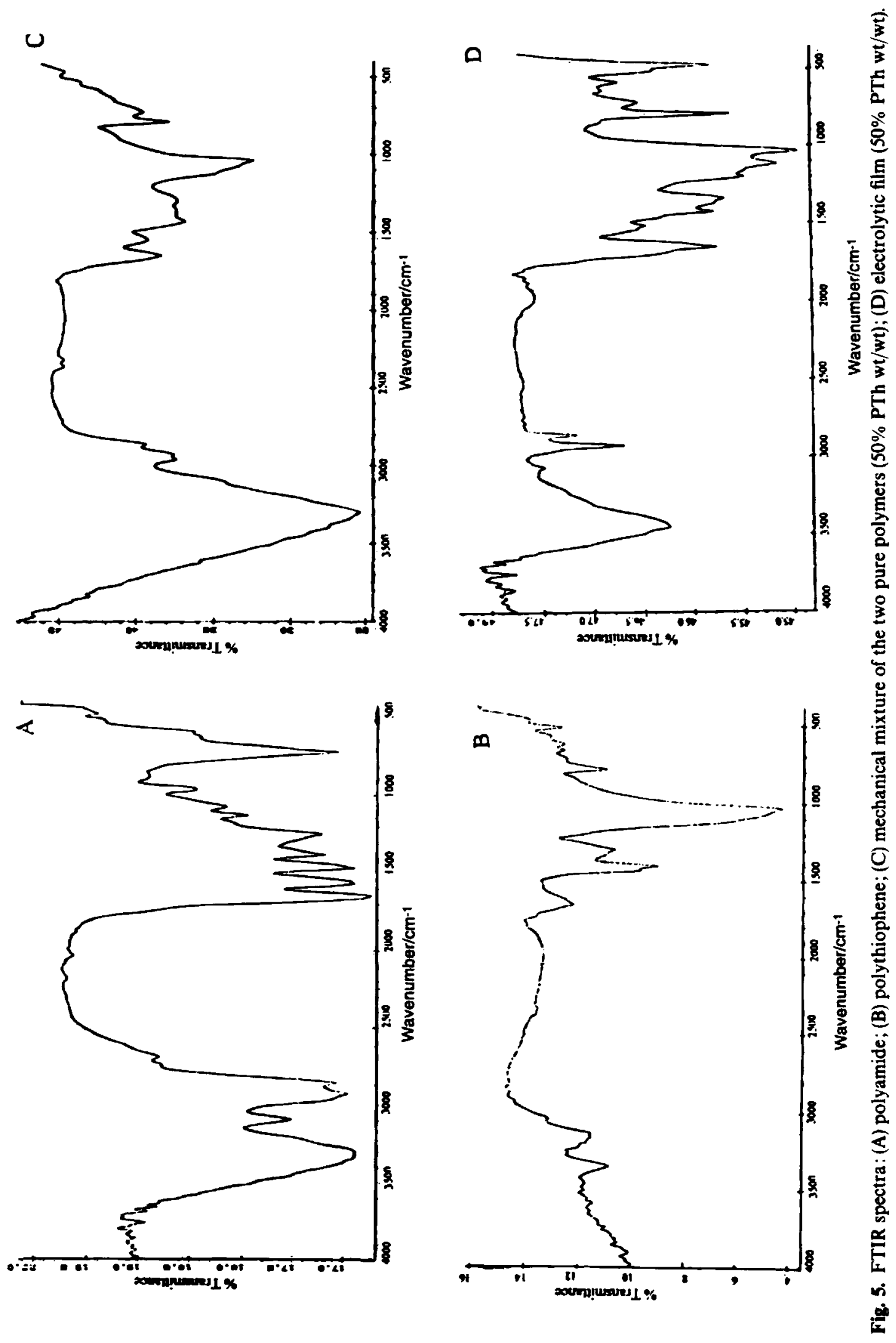


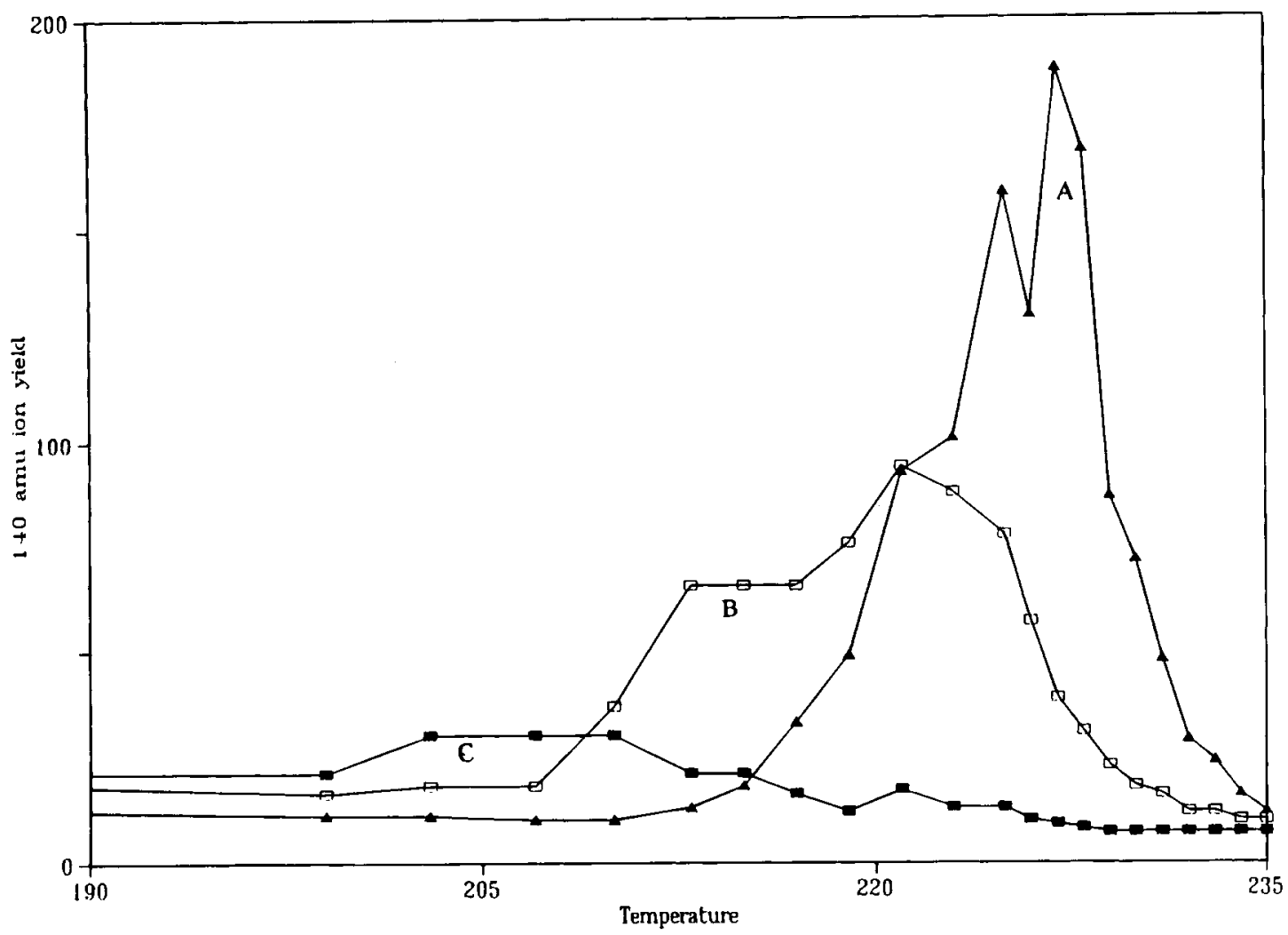

Fig. 6. Direct pyrolysis: (A) polyamide; (B) mechanical mixture (50\% PTh $w t / w t) ;(C)$ electrolytic film $(50 \% \mathrm{PTh} w \mathrm{wt} / \mathrm{wt})$.

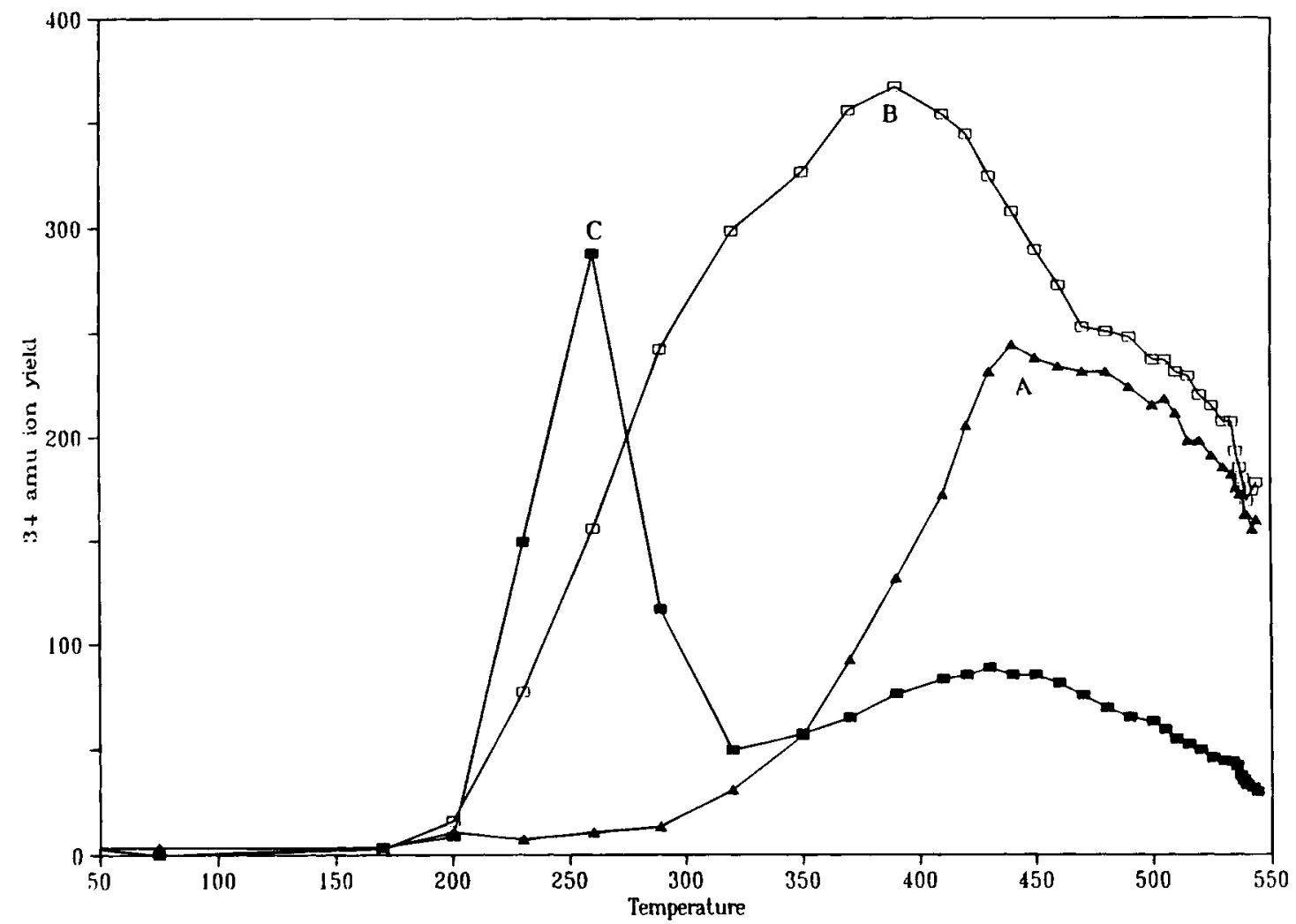

Fig. 7. Indirect pyrolysis: (A) polythiophene; (B) mechanical mixture (50\% PTh wt/wt); (C) electrolytic film (50\% PTh wt/wt). 
secondary amide groups, as a function of temperature during the direct pyrolysis of PA, PA-PTh mechanical mixture and the electrolytic film. These results indicate that extensive chemical processes must have taken place in the PA film during the electrochemical polymerization of thiophene.

Indirect pyrolysis evolved-gas analysis data also support the direct pyrolysis findings. A particular point that should be mentioned is $\mathrm{H}_{2} \mathrm{~S}$ formation (Fig. 7). During the indirect pyrolysis of $\mathrm{PTh}, \mathrm{H}_{2} \mathrm{~S}$ generation occurred at elevated temperatures. This indicates that its production is mainly due to secondary reactions of sulphur produced in the initial stages of decomposition. The presence of PA in the pyrolysis chamber enhanced $\mathrm{H}_{2} \mathrm{~S}$ production. Yet it is clear from the figure that its generation during the thermal degradation of the electrolytic film was much more pronounced. The production of $\mathrm{H}_{2} \mathrm{~S}$ in the low temperature range in this sample may be due to expulsion of HS from the polymer chain, which can further react to produce $\mathrm{H}_{2} \mathrm{~S}$ even at low temperatures. The presence of HS may be additional evidence for chemical interactions between PA and PTh in the electrolytic film.

A detailed study of the thermal degradation products of the samples is in progress.

\section{CONCLUSIONS}

Thermal and spectroscopic studies support the evidence for the existence of an alloy film formed by the two polymers, PA and PTh. SEM micrographs of the composites show that PTh diffuses through the host polymer (PA), producing a uniform network in the composite. Pyrolysis analysis of the electrolytic films reveals that there exists a possible chemical interaction between the insulating and the conducting polymer during the polymerization of thiophene.

\section{ACKNOWLEDGEMENTS}

This work is partly supported by State Planning Organization (DPT-95-K120498). We also would like to thank Prof. Dr Macit Ozenbas for the SEM micrographs.

\section{REFERENCES}

1 Elsenbaumer, R. L., Jen, K. Y., Miller, G. G. \& Shacklette, L. W., Synth. Met., 118 (1987) 277.

2 Tourillon, G., in Handbook of Conducting Polymers ed. T. A. Skotheim. Dekker, New York, 1986, Vol. 1, p. 293.

3 Kaneto, K., Ura, S., Yoshino, K. \& Inuishi, Y., Jpn J. Appl. Phys., 23 (1984) L189.

4 Dogan, S., Akbulut, U., Yalçin, T., Süzer, S. \& Toppare, L., Synth. Met., 60 (1993) 27.

5 Braun, D., Moses, D., Zhang, C. \& Heeger, A. J., Synth. Met., 55-57 (1993) 4145.

6 Tanaka, K., Shichiri, T., Wang, S. \& Yanabe, T., Synth. Met., 24 (1988) 203 .

7 Tourillon, G. \& Garnier, F., J. Electroanal. Chem., 135 (1982) 173.

8 Ruckenstein, E. \& Park, J. S., Synth. Met., 44 (1991) 293.

9 Inganas, O., Liedberg, B. \& Ru, W. C., Synth. Met., 11 (1985) 239.

10 Otero, T. F. \& Azelain, E. de Larreta, Polymer, 29 (1988) 1522.

11 Danieli, R., Taliani, C., Zamboni, R., Giro, G., Biserni, M., Mastragostino, M. \& Testoni, A., Synth. Met., 13 (1986) 325.

12 Kaneto, K., Kohno, Y., Yoshino, K. \& Inuishi, Y., J. Chem. Soc., Chem. Commun., ?? (1983) 382.

13 Wang, H. L. \& Fernandez, J. E., Macromolecules, 26 (1993) 3336.

14 Selampinar, F., Akbulut, U., Yalçin, T., Süzer, S. \& Toppare, L., Synth. Met., 62 (1994) 201.

15 Ojio, T. \& Miyata, S., Polym. J., 18 (1986) 95.

16 Niwa, O. \& Tamamura, T., J. Chem. Soc., Chem. Commun., ?? (1984) 817.

17 Wessling, B. \& Volk, H., Synth. Met., 15 (1986) 183.

18 Han, J. H., Motobe, T., Whang, Y. E. \& Miyata, S., Synth. Met., 45 (1991) 261 .

19 Wang, H. L., Toppare, L. \& Fernandez, J. E., Macromolecules, 23 (1990) 1053.

20 Fares, M. M., Yalçin, T., Hacaloglu, J., Güngör, A. \& Süzer, S., Analyst, 119 (1994) 693.

21 Fares, M. M., Hacaloglu, J. \& Süzer, S., Eur. Polym. J., 7 (1994) 845. 